\title{
Affective Structures among Students and its Relationship with Academic Burnout with Emphasis on Gender
}

\section{Somaye Bikar}

MA Student of Educational Psychology, University of Sistan and Baluchestan, Iran

\section{Afsaneh Marziyeh}

Asst. Prof., corresponding author, Faculty of Educational Sciences and Psychology, University of Sistan and Baluchestan, Zahedan, Iran, marziyeh@ped.usb.ac.ir

\section{Abdolwahab Pourghaz}

Assoc. Prof., Department of Educational Sciences, Faculty of Educational Sciences and Psychology, University of Sistan and Baluchestan, Zahedan, Iran

$$
\begin{aligned}
& \text { This study aimed to determine the relationship between affective structures and } \\
& \text { academic burnout among male and female third-grade high school students in } \\
& \text { Zahedan in the academic year } 2016-2017 \text {. The current descriptive-correlational } \\
& \text { study had a sample including } 362 \text { students selected using a multistage cluster } \\
& \text { sampling method. To collect data, Academic Burnout Questionnaire (Berso et al., } \\
& \text { 1997) and Positive and Negative Affect Schedule (Watson et al., 1988) were used. } \\
& \text { Results of the present study indicated that positive affect was significantly and } \\
& \text { diversely correlated to subscales of academic burnout (academic fatigue, academic } \\
& \text { apathy, and academic inefficiency). Moreover, negative affect was significantly } \\
& \text { and directly correlated to all the subscales of academic burnout. Results of an } \\
& \text { independent t-test demonstrated that there were no significant differences between } \\
& \text { the male and female students with regard to positive and negative eafects. } \\
& \text { However, academic burnout was higher among the male students compared to their } \\
& \text { female counterparts. Furthermore, results of a stepwise regression analysis showed } \\
& \text { that in the first step, positive affect alone predicted } 22 \% \text { of the variance in } \\
& \text { academic burnout and, in the second step, negative affect increased the power of } \\
& \text { predicting academic burnout to } 28 \% \text {. Given the predictive power of affective } \\
& \text { structures ( } 28.2 \%, \text { p }<0.001 \text { ), they can be affectively applied to prevent academic } \\
& \text { burnout. }
\end{aligned}
$$

Keywords: affective structures, positive affect, negative affect, academic burnout, students 


\section{INTRODUCTION}

One of the most important goals of education systems in today's world, which has always been the attention of researchers, is the development of motivated, purposeful, progressive, and productive learners. The opposite with academic achievement, is academic failure, and academic burnout. The term burnout was scientifically used, for the first time, by a psychiatrist named Freudenberger (1974). Conventionally, burnout is considered as a three-component syndrome: emotional exhaustion, depersonalization, and reduced individual accomplishment, which is measured by the Maslach Burnout Inventory (Maslach \& Leiter, 1997). Emotional exhaustion refers to the feeling of being empty and depleted from individual emotional resources as a component of individual stress (Maslach \& Leiter, 1997). The depersonalization refers to negative pessimistic or excessive responses with anxiety other people in the workplace show as an interpersonal component of burnout (Maslach et al, 2001). Finally, the reduced individual accomplishment refers to a lack of sense in the suitability and fertility rate, and low level of self-efficacy, which includes the component of burnout self-assessment (Schaufeli \& Baunk, 2002). In recent years, burnout has expanded to educational contexts and situations and is mostly mentioned as academic burnout (Salmela-Aro et al., 2008).

Neuman (1990) proposed the term academic burnout for the first time. Academic burnout is characterized by several features including having a sense of exhaustion caused due to academic demands and requirements (academic fatigue), having a growing pessimistic sense and lack of interest in academic tasks (academic apathy), and having a poor personal development in academic and educational affairs (academic inefficiency). Although learners do not work in an educational setting as an employee; or they do not have any special occupation; but from a psychological view, their teaching and learning activities can be considered as a "work" (Salmela-Aro et al., 2008). They attend classrooms and do a set of assignments for exam success and earning a score. People with academic burnout usually have symptoms such as anxiety over the content of the course, the inability to continue to attend classrooms, not participating in classroom activities, feeling meaningless in classroom activities, feeling inability to learn lessons and eventually dropping out Study experience (Naami, 2009). Nowadays, academic burnout is a major concern of families and education authorities. In addition to its adverse effects on the national economy, academic burnout has negative impacts on students' mental health (Eslami, 2011).

Among other significant factors affecting learning and academic burnout among students, positive and negative effects, known as affective structures, can be mentioned. Affects are an essential part of the dynamical system of human personality. Characteristics and affective changes, how to communicate affectively, and to interpret and understand the affections of others, have a role in the growth of the personality organization, moral development, social relations, the formation of identity and concept (Berke, 2013). Indeed, effects refer to a student's interest in doing his/her assignments (Dinner \& Emmons, 1984). Watson and Tellegen (1985) divided affects into two basic affective dimensions. One of these dimensions is negative affect which is defined as the extent to which a person is dissatisfied and has an unpleasant feeling. In contrast, 
positive affect refers to the extent to which a person experiences joy, alertness, and involvement in enjoyable tasks. Various studies have indicated that positive and negative emotions can play key roles in predicting and modifying health consequences and can act in accordance with different mood states; since most of the feelings students experience in a learning environment are recognized through their relationships with a number of important outcomes such as academic achievement and academic adjustment as well as physical and psychological health and well-being (Salkowski et al., 2012).

Pekron et al. (2009) argue that positive effects, such as hope and pride can be rooted in students' academic performance. Savari and Boshlideh (2010) in their research, have shown the relationship between personality traits and negligence and academic consistency with academic burnout in high school students. In their view, the mentally disabled are constantly blaming themselves and experiencing a lot of stress and anxiety in dealing with everyday events, especially academic affairs, which can reduce personal and pessimistic attitudes toward School activities, which, according to Salmela-Aro et al.(2008), are important factors affecting academic burnout. Negative affect makes students be less active (Reynolds \& Weigand, 2010) and is closely associated with emotional exhaustion and academic stressors (Márquez et al., 2006). In their study, Saklofske et al. (2007) showed that negative affect and its dependence on stress among students were related to academic failure. In another study, Lin and Huang (2014) reported that the status of academic burnout among university students was lower than the moderate level. Vahedi et al. (2014) demonstrated that academic experience and neuroticism were significantly correlated with academic burnout. Additionally, they revealed that self-efficacy, internal valuation, and self-regulation were negatively associated with academic burnout.

Zahedbablaan et al. (2014), in their study, concluded that academic burnout was higher among male students compared to that of their female counterparts. On the other hand, Azimi and Piri (2013) revealed that there were no significant differences between male and female students with regard to academic burnout.

Michaeli et al. (2014) reached a conclusion that female students had higher emotion regulation and positive affect and experienced lower academic burnout compared to male students. However, considering negative affect and academic performance, no significant differences were found between these two groups. Marzoughi et al. (2013) showed that there were no significant differences between male and female students in terms of academic burnout.

Neuman (1990) argues that for some reason, academic burnout is one of the major research areas of schools. The first reason is that academic burnout can be a key to understanding the various behaviors of students, such as academic performance during the period of study. The second reason is that academic burnout affects students 'relationship with school. Thirdly, academic burnout can affect students' enthusiasm and enthusiasm for continuing education. Given these important points, identifying variables predicting academic burnout is one of the key issues in this field. 
Therefore, given the discussed theoretical and practical background and taking the significance of academic burnout and identifying the factors affecting it and considering the sensitivity of the high school in terms of time, due to university connection and employment and situational sensitivity due to synchronization with adolescence and puberty, the purpose of this study was to investigate the relationship between affective structure of high school students with academic burnout. In the light of this goal, answers were sought to the following research questions:

1- Is there a significant relationship between the student's affective structure (Positive \& Negative affective) and academic burnout?

2- Which subscale of students' affective structures can predict academic burnout?

3- What is the degree of student's burnout?

4- Is there a significant difference between female and male students in affective structure?

5- Is there a significant difference between female and male students in academic burnout?

\section{METHOD}

\section{Research Methodology}

Considering its objectives, this study was an applicable research since its results could be used to solve existing problems. However, in terms of methods of collecting data and given the main goal of conducting the current study, i.e. examining the relationship between affective structures and academic burnout, this descriptive study followed a regression design.

\section{Statistical Population}

This study had a statistical population including all male and female third-grade high school students in Zahedan in the academic year 2016-2017. According to General Directorate of Education, there were 6386 high school students in Zahedan.

\section{Sample and Sampling Method}

With regard to size of the statistical population (6386), using the Cochran's Formula, the sample size was obtained as 362 .

$n=\frac{N t^{2} \cdot p q}{N d^{2}+t^{2} \cdot p q}=\frac{6386(1 / 96)^{2} \times(0 / 5)(0 / 5)}{6386(0 / 05)^{2}+(1 / 96)^{2}(o / 5)(0 / 5)}=362.36$

To select the sample, a multistage cluster sampling method was applied. In this regard, 6 schools ( 3 schools for girls and 3 schools for boys) were chosen from each district of 
Zahedan (districts 1 and 2). Afterward, 2 classes were selected from each school. Then, the sample was randomly selected from each class.

\section{Data Collection Tools}

To collect the data, the following measurement tools were applied.

\section{The Academic Burnout Questionnaire (Berso et al., 1997)}

This questionnaire assesses 3 subscales including academic fatigue, academic apathy, and academic inefficiency and was designed and validated by Berso et al. in 1997. This questionnaire, which has 15 items, is scored based on a 5-point Likert-type scale (ranging from totally disagree (1) to totally agree (5)). 5 items measure academic fatigue, 4 items evaluate academic apathy (pessimism), and 6 items assess academic inefficiency. The items related to academic inefficiency are scored reversely. The items associated with the subscales of this questionnaire are presented in Table 1.

Table 1

The items related to the subscales of the Academic Burnout Questionnaire

\begin{tabular}{ll}
\hline Subscales & Items \\
\hline Academic fatigue & $1,4,7,10,13$ \\
\hline Academic apathy (pessimism) & $2,5,11,14$ \\
\hline Academic inefficiency & $3,6,8,9,12,15$ \\
\hline
\end{tabular}

Berso et al. (1997) reported that the Cronbach's alpha coefficient of academic fatigue, academic apathy, and academic inefficiency was respectively $0.70,0.82$, and 0.75 . Moreover, using a confirmatory factor analysis, results indicated that validity indices of this questionnaire were all desirable (Berso et al., 1997). In the current study, Cronbach's alpha coefficients of the whole questionnaire, academic fatigue, academic apathy, and academic inefficiency were $0.86,0.75,0.74$, and 0.68 , respectively.

The Positive and Negative Affect Schedule (Watson et al., 1988)

This self-report scale includes 20 items and was developed and standardized by Watson et al. (1988). It evaluates 2 subscales including positive affect and negative affect. Each item is answered based on a 5-point Likert-type scale ranging from not at all (1) to very high (5). It should be noted that by changing the instruction of conducting the test, both personality states and personality traits can be measured. When this test evaluates the extent to which a subject has felt a certain feeling over the past week, personality states are evaluated and when it assesses the way the subject felt during a longer period of time, personality traits are measured. Each subscale (positive affect and negative affect) is assessed via 10 items. Scores range from 10 to 50. The items related to the subscales of this schedule are presented in Table 2.

Table 2

The items related to the subscales of the Positive and Negative Affect Schedule

\begin{tabular}{ll}
\hline Subscales & Items \\
\hline Positive affect & $1,3,5,9,10,12,14,16,17,19$ \\
\hline Negative affect & $2,4,6,7,8,11,13,15,18,20$ \\
\hline
\end{tabular}


Watson et al. (1988) reported that Cronbach's alpha coefficients of positive affect and negative affect were 0.88 to 0.87 , respectively. In addition, the test-retest reliability assessed with an eight-week interval for positive affect and negative affect was 0.68 and 0.71 , respectively. In terms of validity, correlations among the subscales of this test and several other measurement tools which included structures related to these effects, including anxiety and depression, were high. For an instance, the correlation between negative affect and Beck Depression Inventory was 0.58 and the correlation between positive affect and this inventory was -0.36 . Additionally, the correlation between negative affect and Obvious-Hidden Anxiety Scale was 0.51 and the correlation between positive affect and this scale was -0.35 . These correlations indicated the high concurrent validity of the Positive and Negative Affect Schedule (Watson et al., 1988). In the present study, using a Cronbach's alpha coefficient, the reliability of positive affect and negative affect was respectively 0.76 and 0.84 .

\section{Procedure}

To answer the research questions, after getting permission from General Doctorate of Education in Zahedan and assessing the validity of the applied questionnaires, both questionnaires were distributed among the sample at the same time by referring to the selected schools. All necessary explanations on the method of filling out the questionnaires were provided.

\section{Data Analysis}

For data analysis, a Pearson correlation coefficient, a stepwise regression analysis, an independent $\mathrm{t}$-test, and a one-sample t-test were used. All statistical analyses were conducted via SPSS.

\section{FINDINGS}

To examine the relationship of positive and negative effects with the subscales of academic burnout, the Pearson correlation coefficient was applied, results of which are presented in Table 3.

Table 3

Correlation matrix of positive and negative affects with the subscales of academic burnout

\begin{tabular}{lllllll}
\hline & 1 & 2 & 3 & 4 & 5 & 6 \\
\hline Academic apathy & 1 & & & & & \\
\hline Academic fatigue & $0.721^{* *}$ & 1 & & & & \\
\hline Academic inefficiency & $0.554^{* *}$ & $0.457^{* *}$ & 1 & & & \\
\hline Positive affect & $-0.384^{* *}$ & $-0.332^{* *}$ & $-0.485^{* *}$ & 1 & & \\
\hline Negative affect & $0.395^{* *}$ & $0.346^{* *}$ & $0.248^{* *}$ & $-0.309^{* *}$ & 1 & \\
\hline Academic burnout & $0.884^{* *}$ & $0.868^{* *}$ & $-0.789^{* *}$ & $-0.471^{* *}$ & $0.387^{* *}$ & 1 \\
\hline$* * \mathrm{P}<0.01$ & & & & & &
\end{tabular}

The results presented in the above table show that positive affect is significantly and diversely related to the subscales of academic burnout (academic apathy, academic fatigue and academic inefficiency). Moreover, negative affect is significantly and 
directly related to the subscales of academic burnout (academic apathy, academic fatigue and academic inefficiency).

To examine which subscale of students' affective structures can predict academic burnout among them, the stepwise regression analysis was used.

Table 4

Results of the stepwise regression analysis conducted to predict academic burnout via the students' affective structures

\begin{tabular}{|c|c|c|c|c|c|c|c|c|c|c|c|}
\hline $\begin{array}{l}\text { Criterion } \\
\text { variable }\end{array}$ & Pattern & $\begin{array}{l}\text { Variables } \\
\text { entered into the } \\
\text { equation } \\
\text { respectively }\end{array}$ & $\mathrm{R}$ & $\mathrm{R}^{2}$ & $A D j-R^{2}$ & SE & B & B & $\mathrm{F}$ & $\mathrm{T}$ & Sig \\
\hline \multirow{2}{*}{\multicolumn{2}{|c|}{$\begin{array}{l}\text { Academic Stepwise } \\
\text { burnout }\end{array}$}} & Positive affect & 0.471 & 0.222 & 0.220 & 9.38 & -0.642 & -0.471 & 102.62 & -10.13 & 0.00 \\
\hline & & Negative affect & 0.535 & 0.286 & 0.282 & 8.99 & 0.325 & 0.267 & 72.05 & 5.701 & 0.00 \\
\hline
\end{tabular}

The results of the stepwise regression analysis presented in Table 4 indicate that the correlation coefficient $(\mathrm{R})$ between positive and negative affective with academic burnout is 0.535 and 0.471 , respectively. Calculated $R^{2}$ shows that in the first step, positive affect predicts $22 \%$ of the variance in academic burnout. In the second step, negative affect increases the predictive power by $0.06 \%$ and positive and negative effects together predict $28 \%$ of the variance in academic burnout. The calculated $\beta$ value $(-0.471)$ indicates that positive affect has a larger contribution to the prediction of academic burnout. Regarding the significant level $(\mathrm{P}<0.001)$, the applied regression model, is an appropriate predictor of academic burnout.

To investigate the difference in affective structures among the male and female students, the independent t-test was used, results of which are presented in Table 5.

Table 5

The results of the independent t-test carried out to examine the difference in affective structures and academic burnout based on gender

\begin{tabular}{lllllll}
\hline $\begin{array}{l}\text { Variable } \\
\text { Independent }\end{array}$ & $\begin{array}{l}\text { Variable } \\
\text { Gender }\end{array}$ & $\mathrm{N}$ & $\mathrm{M}$ & $\mathrm{SD}$ & $\mathrm{T}$ & Sig \\
\cline { 1 - 5 } Positive affect & Female & 181 & 34.92 & 7.76 & \multirow{2}{*}{-0.944} & 0.346 \\
\cline { 2 - 5 } & Male & 181 & 35.70 & 7.82 & & \\
\hline Negative affect & Female & 181 & 29.09 & 8.51 & 0.625 & 0.532 \\
\cline { 2 - 5 } & Male & 181 & 28.52 & 8.96 & & \\
\hline Academic burnout & Female & 181 & 39.56 & 10.40 & -3.162 & 0.002 \\
\cline { 2 - 5 } & Male & 181 & 43.05 & 10.56 & & \\
\hline
\end{tabular}

The results in the table above show that the female students' mean in the positive and negative effects were 29.09 and 34.92 with a standard deviation of 8.51 and 7.76 , and male students' mean 52.28 and 35.70 , with a standard deviation 8.96 and $82 / 7$. The results presented in this table demonstrate that the male students' mean scores on positive affect and negative affect are different from female students. However, this 
difference is not statistically significant regarding to calculated $\mathrm{T}$ for positive and negative affections (0.625 and 0.0494) and significant level ( $\mathrm{P}>0.05)$.

In academic burnout, female students had mean of 36.56 with a standard deviation of 10.40 and male students' mean of 40.55 with a standard deviation of 10.56 . Furthermore, considering to calculated $\mathrm{T}(-3.162)$ for academic burnout, the male students' mean score is greater than that of the female students and this difference is statistically significant $(\mathrm{P}<0.01)$.

To evaluate the statuses of affective structures and academic burnout among the students, the one-sample t-test was applied, results of which are presented in Table 6.

Table 6

The results of the one-sample t-test carried out to evaluate the statuses of affective structures and academic burnout among the students

\begin{tabular}{llllllll}
\hline Variable & $\mathrm{N}$ & $\mathrm{M}$ & $\mathrm{SD}$ & $\mathrm{T}$ Value & $\mathrm{T}$ & $\mathrm{df}$ & $\mathrm{Sig}$ \\
\hline Positive affect & 362 & 35.31 & 7.79 & 30 & 12.97 & 361 & 0.00 \\
\hline Negative affect & 362 & 28.81 & 8.74 & 30 & -2.58 & 361 & 0.00 \\
\hline Academic burnout & 362 & 41.31 & 10.61 & 45 & -6.60 & 361 & 0.00 \\
\hline Academic fatigue & 362 & 16.005 & 4.58 & 15 & 4.17 & 361 & 0.00 \\
\hline Academic apathy & 362 & 11.12 & 3.75 & 12 & -4.42 & 361 & 0.00 \\
\hline Academic inefficiency & 362 & 14.17 & 4.20 & 18 & -17.29 & 361 & 0.00 \\
\hline
\end{tabular}

The results presented in this table show that the students' mean score on positive affect (35.31) is significantly greater than the mean (30). With respect to $(t=12 / 97, \mathrm{df}=361)$ this difference is significant $(\mathrm{P}<0.001)$. Therefore, the status of positive affect among the students under study is higher than the moderate level. Considering negative affect, the students' mean score (28.81) is significantly lower than the mean (30). With respect to $(\mathrm{t}=-2.58, \mathrm{df}=361)$ this difference is significant $(\mathrm{P}<0.001)$. Hence, the status of negative affect among the students under study is lower than the moderate level.

With regard to academic burnout, the students' mean score (41.31) is lower than the mean (45). With respect to $(\mathrm{t}=-6.60, \mathrm{df}=361)$ this difference is significant $(\mathrm{P}<0.001)$. This means that the status of academic burnout among the students under study is lower than the moderate level. Considering academic fatigue, the students' mean score (16.005) is greater than the mean (15). With respect to $(t=4.17, \mathrm{df}=361)$ this difference is significant $(\mathrm{P}<0.001)$.Therefore, the status of academic fatigue among the students under study is higher than the moderate level. With regard to academic apathy, the students' mean score (11.12) is lower than the mean (12). With respect to $(t=-4.42$, df $=361)$ this difference is significant $(\mathrm{P}<0.001)$. Hence, the status of academic apathy among the students is lower than the moderate level. The students' mean score on academic inefficiency (14.17) is lower than the mean (18). With respect to $(t=-17.29 \mathrm{df}$ $=361)$ this difference is significant $(\mathrm{P}<0.001)$. This means that the statuses of academic inefficiency are lower than the moderate levels. 


\section{DISCUSSION AND CONCLUSION}

The present study aimed to examine the relationship of affective structures with academic burnout among the students. The results of this study showed that positive affect was significantly and diversely related to the subscales of academic burnout. This finding is in line with results of Saklofske et al. (2007), Salkowski et al. (2012), Vahedi et al. (2014), and Michaeili et al. (2014) which indicated that there was a correlation between positive affect (or its realizations) and academic burnout. To explain this finding, it can be noted that several previously carried out studies indicated that gentle and positive emotional states can particularly affect daily thinking processes. Having positive emotions is a sign of having positive information in memory and vice versa. When stressful conditions, like attending a school, are accompanied with positive effect, people usually show a lot of effort and employ lots of energy to achieve their goals.

Additionally, the results indicated that negative affect was significantly and directly related to the subscales of academic burnout. This finding is consistent with results of Saklofske et al. (2007), Salkowski et al. (2012), Vahedi et al. (2014), and Michaeili et al. (2014) which revealed the relationship between negative affect and academic burnout. Negative affect leads to loss of energy and personal resources. People who experience high levels of negative affect are usually anxious and worried and they usually have low levels of energy. Experiencing negative affect leads to achieve low levels of performance.

According to the results of the current study, academic burnout was higher among the male students compared to their female counterparts. This finding is in agreement with results of Zahed Bablaan et al. (2014) and Michaeili et al. (2014); however, it is not consistent with results of Azimi and Piri (2013) and Marzoughi et al. (2013). To explain this finding, it can be mentioned that male and female students have different academic motivations and concerns about unemployment have significant impacts on male students. Hence, there is a possibility that male students, compared to female students, experience higher levels of academic pressure and have additional concerns. In this regard, these factors can exacerbate academic burnout among male students.

Considering positive and negative effects, no significant differences were found between the male and female students under study. This finding is not in line with results of Michaeili et al. (2014) which demonstrated that female students experienced higher levels of positive affect compared to their male counterparts. It is likely that the possibility of continuing education provides more positive feedbacks for female students compared to male students. This may create more positive emotions among female students. It should also be noted that the results of this study are consistent with a part of results obtained from the study conducted by Michaeili et al. (2014) which revealed that there were no significant differences between male and female students with regard to negative effect. However, unlike the results of this study, many social psychologists believe that the concept of self is different in male and female students. When defining self, male students mainly focus on uniqueness. Conversely, female students' schemas mostly put the emphasis on emotions, relations, and being related to others. 
Furthermore, another result of this study revealed that the status of academic burnout among the students was lower than the moderate level. This finding is in line with results of Lin and Huang (2014) which indicated that the status of academic burnout among students was lower than the moderate level.

Finally, the results of the present study indicated that positive and negative effects predicted the variance in academic burnout among the students. Therefore, given the obtained results, it can be concluded that an increase in positive affect and an improvement in the method of controlling negative affect can play key roles in the prevention of academic burnout.

In this regard, to improve positive effect, reduce negative effect, and prevent the incident of academic burnout among students, course planners are highly recommended to revise school curriculums and pay attention to students' interests and community needs when planning a course content. Teachers are also advised to be as flexible as possible in matters relating to the class and its programs, and to avoid drastic and unalterable programs. To create emotions and positive emotions in students and as a result, students will suffer less academic burnout. In addition, school administrators and administrators can create a platform for interaction between student and school parents and counselors. Self-awareness and evaluation of students will provide their positive and negative emotions and thus help to solve their problems and concerns and thereby reduce academic burnout.

\section{REFERENCES}

Azimi, M., \& Piri, M. (2013). The relationship of academic burnout and learning selfregulation with academic performance among high school students. Journal of Research in Curriculum Development, 10(11), 116-128.

Berk, L. E. (2013). Exploring life span development (3th ed.). New York: Pearson.

Berso, E., Salanova, M., \& Schoufeli, B. (1997). In search of the third dimension of Burnout. Applied Psychology, 56(3), 460-472.

Dinner, E., \& Emmons, R. A. (1984). The independence of positive and negative affect. Journal of Personality and Social Psychology, 47, 1105-1117.

Eslami, M. A. (2010). The relationship of spiritual intelligence and mental-physical health with academic burnout among students of Allameh Tabatabai University (MA Thesis). Tehran: Allameh Tabatabai University.

Freudenberger, H. J. (1974). Staff burn-out. Journal of Social Issues, 30, 159-161.

Lin, S. H., \& Huang, Y. C. (2014). Life stress and academic burnout. Journal of Active Learning in Higher Education, 15(1), 77-90.

Márquez, P. G., Martin, R. P., \& Brackett, M. A. (2006). Relating emotional intelligence to social competence and academic achievement in high school students. Psicothema, 18,118-123. 
Marzoughi, R., Heidari, M., \& Heidari, E. (2013). Examine the relationship between educational equity and academic burnout among students of Welfare and Rehabilitation Sciences University. Journal of Strides in Development of Medical Education, Department of Research in and Development of Medical Education, 10(3), 328-334.

Maslach, C., \& Leiter, M. (1997). The truth about burnout: How organizations cause personal stress and what to do about it. San Fransisco, CA: Jossey-Bass.

Masalach, C., Schaufeil, W. B., \& Liter, M. P. (2001). Job burnout, annual review of psychology, 52, 397- 422.

Michaeili, L., Rajabi, S., Abbasi, M., \& Zamanlou, Kh. (2014). The relationship of emotion regulation and positive and negative emotions with academic performance and academic burnout among university students. Educational Psychology, 2(32), 31-54.

Naami, A. (2009). The relationship between quality of learning experiences and academic burnout among students of Shahid Chamran University of Ahvaz, Psychological studies, 5(3), 117- 134.

Neuman, Y. (1990). Determinant and consequences of student Burnout in universities. The Journal of Higher Education, 61(1), 20-31.

Reynolds, A.L., \& Weigand, M.J. (2010). The relationships among academic attitudes, psychological attitudes, and the first-semester academic achievement of first year college students. Journal of Student Affairs Research and Practice, 47(2), 175-195.

Saklofske, D. H., Austin, E. J., Rohr, B. A., \& Andrews, J. W. (2007). Personality, emotional intelligence and exercise. Journal of Health Psychology, 12, 937-948.

Salkowski, M. L., Joyce, D. K., \& Stroch, E. A. (2012).Treating childhood anxiety in schools: service delivery in a response to intervention paradigm. Journal of Child and Family Studies, 21(6), 938-947.

Salmela-Aro, K., Kiuru, N., Pietikainen, M., \& Jokela, J. (2008). Does School matter? The role of school context for school burnout. European Psychologist, 13, 1-13.

Savari, K., \& Boshlideh, K. (2010). The relationship between personality characteristics and academic burnout among high school students in Ahwaz. Journal of Psychological Achievements, 4(1), 89- 102.

Schaufeli, W. B., \& Baunk, B. P. (2002). Burnout: An overview of 25 years of research and theorizing. In M. J. schabracq, J. A. M ninnubst, \& c.l.cooper (Eds.), Handbook of work and health psychology. New York: Wiley \& Sons.

Vahedi, Sh., Hashemi, T., \& Shafiee Surak, S. (2014). The impact of educational experience, neuroticism, and learning self-regulation strategies on academic burnout: Test a conceptual model. Knowledge and Research in Applied Psychology, 15(3), 7180 . 
Watson, D., Clark, L. A., \& Tellegen, A. (1988). Development and validation of a brief measure of positive and negative affect: The PANAS scales. Journal of Personality and Social Psychology, 54(6), 1063-1070.

Watson, D., \& Tellegen, A. (1985). Toward a consensual structure of mood. Psychological Bulletin, 98(2), 219-235.

Watson, D., Clark, L. A., \& Carey, G. (1988). Positive and negative affectivity and their relation to anxiety and depression disorders. Journal of Abnormal Psychology, 97, 346353.

Zahedbablaan, A., Pourbahram, R., \& Rahmani Javanmard, S. (2014). The relationship of perfectionism, goal orientation, and academic performance with academic burnout. Journal of New Approaches in Educational Management, 5(18), 109-124. 